\title{
A New Approach to Creation of an Artificial Intellect and Method of its Implementation
}

\author{
Wladimir Stalski \\ L.-Uhland Straße 19 \\ 54293 Trier \\ Germany
}

WSTALSKI@YAHOO.DE

Editor: Farshad Badie

\begin{abstract}
On the basis of the author's earlier works, the article proposes a new approach to creating an artificial intellect system in a model of a human being that is presented as the unification of an intellectual agent and a humanoid robot (ARb). In accordance with the proposed new approach, the development of an artificial intellect is achieved by teaching a natural language to an ARb, and by its utilization for communication with ARbs and humans, as well as for reflections. A method is proposed for the implementation of the approach. Within the framework of that method, a human model is "brought up" like a child, in a collective of automatons and children, whereupon an $\mathrm{ARb}$ must master a natural language and reflection, and possess self-awareness. Agent robots (ARbs) propagate and their population evolves; that is ARbs develop cognitively from generation to generation. ARbs must perform the tasks they were given, such as computing, whereupon they are then assigned time for "private life" for improving their education as well as for searching for partners for propagation. After having received an education, every agent robot may be viewed as a "person" who is capable of activities that contain elements of creativity. The development of ARbs thanks to the evolution of their population, education, and personal "life" experience, including "work" experience, which is mastered in a collective of humans and automatons.
\end{abstract}

Keywords: agent, cognitive development, propagation, evolution, artificial personality.

\section{Introduction}

In our article, we use the terms "agent" and "intellectual agent" adopted in (Russel and Norwig, 2006) where "agent" is the name for a computer system, which possesses "some attributes and In our article, we use the terms "agent" and "intellectual agent" adopted in (Russel and Norwig, 2006) where "agent" is the name for a computer system, which possesses "some attributes and properties inherent to reason". We have already considered the creation of a model homo sapiens on the basis of an intellectual agent and a humanoid robot (Salski, 2018), while the matters of "propagation" of agents, "life purpose" of agent robots, and the evolution of their population were proposed earlier in our article (Stalsky, 2014). 
The theory of artificial intelligence (AI) views two approaches to the creation of AI systems: Top-Down AI, and semiotic and Bottom-UP AI; the biological one. The biological approach models biological elements. It includes electronic neuron networks and evolutionary methods of intellectual development. The approach proposed by us and the method of solving its tasks can also be categorized as a biological approach. The goal of our work is to build a new approach. More specifically, we consider the creation and consistent development of an agent knowing and using a natural language that is united with a robot (that is an agent robot (ARb)), the path of development of an ARb as an artificial personality, and creation of a population of ARbs. As compared to an "intellectual agent" (Russel and Norwig, 2006; Gorz, Schneeberger, and Schmid, 2014), the agent proper, the "brain" of an ARb must also know a natural language (NL).

$\mathrm{AI}$ is an analogue of human intelligence. Therefore, the construction and improvement of AI is also rational to be carried out as an analogue of the historical development of the human mind. We are sure that there is only one way for automata to obtain a mind similar to the human mind, namely, mastering the natural language by automata. For the implementation of the proposed new approach, we propose a method of teaching an ARb a natural language (which is needed for human thinking). Reflections, abstract planning, abstract concepts and solutions received by an ARb's "brain" agent directly in NL allow the ARb to progress to meaningful actions in the real world.

It is proposed that the new approach to the creation of the model will be based on the concept of sequential utilization of the maximum analogy of an ARb with a human being. First and foremost, this is mastering a natural language by an agent, as well as "sexual" reproduction of ARbs which imitates "natural selection", and the creation of a community of models; that is a population of ARbs that communicates with humans. This article considers only the initial stage of the "life" of ARbs.

As a present-day human being develops from birth to the age of around 5-7 years, he or she travels a path similar to that of the development of a population of humans from the child of "primitive man" to a first-grader in a present-day primary school. In every human's life, this period predetermines his or her cognitive development in his or her further life as well (Palmer and Palmer, 2003; Smirnova, 2006; Ermakova, 2007).

In view of "Mowgli Syndrome" (Palmer and Palmer, 2003; Smirnova, 2006) that is well known to scientists, we shall adopt two principal theses in our work: (1) A child, as well as an $\mathrm{ARb}$ child, should be able to master a natural language at the beginning of his or her life (Smirnova, 2006; Vygotskiy, 1982) in order to become a member of a human (as well as ARb) community. (2) From the beginning of his or her life, a child must be integrated; that is must be brought up, in a social environment of ARb children of its kind, children and adults (Ermakova, 2007; Siegler, DeLoache, and Eisenberg, 2005).

The method of $\mathrm{ARb}$ reproduction proposed by us envisages the creation of a community of technically identical agent robots that is divided into two parts on the basis of gender status. All ARbs get obligatory "instincts" (algorithms), whereupon the main one is the "reproductive instinct", which we adopt as the "life purpose" of the ARbs. Couples for procreation are formed in accordance with this "instinct". When an ARb searches for a partner for procreation, it strives to find one with the best characteristics; higher education, social achievements, as well as the one who has "progeny" with higher characteristics (Stalsky, 2014). Co-education of children and "ARb children" by a teacher is envisaged as well. Education takes place in a "daycare center" where, like all children, a child ARb must learn reflection and a natural language. Children and $\mathrm{ARb}$ children must communicate with the teacher and with each other using natural language. As 
a result of education, an $\mathrm{ARb}$ child, like other children, learns a natural language, as well as some basic rules of behavior in a human community or later in a community of humans and ARbs.

The obligatory algorithms which are common for all ARbs must be installed only in the first generation of ARbs. Subsequently, ARbs "inherit" a set of necessary algorithms together with a multitude of other programs from their "parents"; whereupon, the efficiency of programs can be increased from generation to generation. Children must be taught using up-to-date scientific methods (Smirnova, 2006; Ermakova, 2007; Siegler, DeLoache, and Eisenberg, 2005). Some research works (e.g., Russel and Norwig, 2006; Gorz, Schneeberger, and Schmid, 2014) examine various methods of creating artifacts that possess "artificial intelligence". Human reason, consciousness and brains are often modeled separately from the human body; this corresponds to the definition of AI as a science, which implements human intellectual abilities with the help of computing machines (Russel and Norwig, 2006; Gorz, Schneeberger, and Schmid, 2014; Luger, 2005), but does not facilitate the development of a model brain of a specific human whose brain is closely associated with his or her "being", sensuality, or body. Therefore, we propose educating a child ARb together with children from the moment of "birth". An ARb must exist in a social environment (i.e. in a community of humans and ARbs) from the beginning till the end of its "life", adopting positive experiences from more experienced individuals.

The life period of childhood predetermines to a large extent the level of a human's cognitive development throughout his or her life. A child ARb will develop cognitively, firstly by maturing together with its peers, and later too, as it gets further education (beyond the scope of this article).

The role of the existing AI systems - agents built as computer software-still remains the principal one in the technical implementation of the proposed model. The potential of the causal dynamics of an agent, like other automatons based on modern computers, is high; in principle, it is the same as that of a human brain (Rapoport and Gerts, 2011). An intellectual agent (Russel and Norwig, 2006) that is fully prepared to perform various functions from the moment of its "birth" also gets a number of hardware facilities and appropriate. The "raising" of ARbs as proposed by us (i.e. their education, acquiring knowledge, work ("service") from the moment of "birth" and till the end of the "life") presumes dividing the "life" functions of an automaton into "service" and "personal" ones for the whole period of its existence.

\section{Building an Agent Robot}

The primary education of a child, and first and foremost teaching them a natural language, is the most important period in education, since language functions mastered by the child become the principal functions of his or her thinking (Vygotskiy, 2017). Thinking is impossible without language. Actually a child who has not acquired speech habits and has not learned to understand words in childhood cannot master the basics of logical thinking and, as a matter of fact, cannot become a human who thinks in a normal way. A close relationship between language and thinking is emphasized in many works (for example in Vygotskiy, 1982). The outstanding linguist Leonard Bloomfield states in his monograph (Bloomfield, 1933) directly: "speaking to oneself or thinking". However, this observation needs the following clarification. A healthy human does not "speak to oneself" (aloud); he or she speculates inwardly, using words, concepts, as well as video images; and to lesser extent, audio and other images. We shall also point out Noam Chomsky's works (see, for example, Chomsky, 1968) where a close relationship between the concepts of thought and speech is emphasized. In our model of a human, an automaton must learn a natural language (NL) and, using mainly video images, get an idea of real objects and 
phenomena from its environment in the form of recorded "written" and "read" words, phrases and concepts.

Algorithms implemented by an $\mathrm{ARb}$ and a child $\mathrm{ARb}$, inter alia, "on their own motions (on their own initiative)" are verbal algorithms. They do not include the body algorithms of an ARb (robot) and electronic algorithms of an agent: "instincts", image recognition algorithms (the "eyes" or an ARB) and sound recognition algorithms, algorithms ensuring functioning of memory, and so on. However, verbal algorithms, that are sets of instructions describing the sequence of activities, were and still remain, the main ones (for thousands of years, they were the only ones) for a human, his or her behavior, work, or studies. A human child and a child ARb are taught by a teacher in the same way as children are taught in a daycare center, whereby for children ARbs (from the first ARb generations), the teacher must also play the role of their parents. Children must be taught using up-to-date scientific methods (Smirnova, 2006; Ermakova, 2007; Siegler, DeLoache, and Eisenberg, 2005).

Some research works (for example, Russel and Norwig, 2006; Gorz, Schneeberger, and Schmid, 2014), examine various methods of creating artifacts that possess "artificial intelligence". Human reason, consciousness and brains are often modeled separately from the human body; this corresponds to the definition of AI as a science, which implements human intellectual abilities with the help of computing machines (Russel and Norwig, 2006; Gorz, Schneeberger, and Schmid, 2014; Luger, 2005), but does not facilitate the development of a model brain of a specific human whose brain is closely associated with his or her "being", sensuality, or body. Therefore, we propose educating a child ARb together with children from Intellect humans and ARbs from the beginning till the end of its "life", adopting positive experiences from more experienced individuals. The life period of childhood predetermines to a large extent the level of a human's cognitive development throughout his or her life. A child ARb will develop cognitively, firstly by maturing together with its peers, and later too, as it gets further education (beyond the scope of this article). on three legs, on one leg (pedestal), a writing table, a dining table, and so on. Also, a special verbal algorithm of the agent creates a cluster. All the procedures coincide approximately with those of an adult human (Rapoport and Gerts, 2011). A KBO has sections: Common, Personal and Working ones. The first two of these contain the same sections received by an $\mathrm{ARb}$ from its parents' KBOs, that is parents' joint KBOs form the asis of their progeny's KBO. Gradually, a subjective "internal model of the external world", that is the "embryo of consciousness", is formed in the KBO (Rapoport and Gerts, 2011). An "adult" $\mathrm{ARb}$ already has a large $\mathrm{KBO}$ that also contains a large number of verbal algorithms, which are created or updated by itself. All the "obligatory" organs and "obligatory" algorithms of an ARb are "innate", like the hardware. Everything received in "childhood" by different ARbs may be identical, except the parents" basic "genetic inheritance", which is transferred to every human and to every ARb. When all ARbs become individuals, the contents of their continuously expanding KBOs are different. Comparisons and detection (after sequential examination of a set of examples with film images already mastered and checked by its own practice, whose descriptions are already available in the $\mathrm{KBO}$ ), allow the $\mathrm{ARb}$ to find a match between the target function and the general motivation of phrases: the principal factor for the semantic identification of a newly received message. This can be considered as a version of the inductive teaching method (Russel and Norwig, 2006; Luger, 2005). An ARb must be also equipped with a vocal speech generation device; for that purpose, an ARb may use the word and phrase recordings available in the KBO dictionary (Russel and Norwig, 2006; Galunov and Galunov, 2001).

Images received by an $\mathrm{ARb}$ from the observed environment (including a virtual one) are dependent (in each specific case) on the viewing angle, lighting, and so on. Therefore, on 
different occasions, images of objects as well as actions may differ from one another even in the memory of one and the same ARb. Even more so, different ARbs must have such differences; additionally, the "genes" inherited from parents are of importance for these differences. Thus, the "personality" of every ARb is individual and unique. Images of objects and phenomena from the sections of the dictionary are compared with the images actually perceived by video sensors. Therefore, all the sets of objects perceived by an ARb are finite, but some of them can be very large (for example, the list of images and the names of animals) and therefore, they must be replenished throughout the lifetime of an $\mathrm{ARb}$. The classification of words with their attributes by categories and sections both for the world of nature and for artifacts is available in the KB and is transferred to the KBO along with mastering words and phrases. Gradually, the language of the specific ARb is built. The "ARb brain" agent belongs to the type of "knowledge-based agents" (Russel and Norwig, 2006) and its KB contains background knowledge. Meanwhile, the KBO also stores knowledge learned from the ARb's personal experience.

An ARb supplements perceived words: nouns (Noun Phrase (NP)) and verbs (Verb Phrase (VP)) by extensional attributes, and characteristics of objects and phenomena. Thereby we can have the representation "ANNP" and "AVVP" where "AN" and "AV" are attributes (Russel and Norwig, 2006). With regard to these attributes and comparing the set of available examples, the $\mathrm{ARb}$ uses an algorithm (inherited from its parents) that replenishes the classification section of the KBO, distributing all words by their respective classes, sub-classes, sections, and so on. The list of word-to-image conformities in the $\mathrm{KBO}$ is continuously replenished.

The verification of the words received from a video sensor and meaning an object or a phenomenon (that is search word image matching (SWIM), see (Russel and Norwig, 2006)) are performed by the $\mathrm{ARb}$ that is querying the images in the KB Dictionary. When searching for matches, the upper ontologies of the search tree and the closest subsequent sections at the beginning of teaching the $\mathrm{ARb}$ are missed. The reason is that the perception of the ARb gives an image of circumstances at the ARb's location; this corresponds to the bottom search tree levels. An element in the state space is compared with a similar one found in the ordered set of images of the tree's bottom level, whose elements (members) form a list of images. The range of search for matching images, sounds and words are also determined on the basis of the classification section of the dictionary.

\section{Primary Education of an Agent Robot}

A child $\mathrm{ARb}$ must master a language in the process of education in a collective in a "language environment" (Ermakova, 2007; Siegler, DeLoache, and Eisenberg, 2005; Vygotsky, 2017), first and foremost in a "daycare center" together with children under the direction of a teacher. For mastering words and concepts, a child ARb also needs a virtual world of toys: dolls, toy cars, railway wagons, and so on. Building toy houses, roads, fences, and playing games together with children (possibly invited schoolchildren) in this virtual world will add a lot to the vocabulary bank of a child ARb. Hereinafter, this vocabulary bank will further be developed during the "adult" life of the ARb (on "service" and as a member of an ARb "population"). The principal goal for a child $\mathrm{ARb}$ is learning a natural language (NL): words and concepts (Smirnova, 2006; Ermakova, 2007). For the first generations of ARbs, the teacher also plays the role of their

parents. The teacher must strive to understand the first words and gestures of a child ARb, and understand the automaton's requests and complaints that are not expressed clearly. Possibly, 
some generations later, these functions will be undertaken by ARb parents. So small children accepted to the daycare center will have very similar development levels.

Everything an ARb sees and "learns" throughout its lifetime (including all the objects and actions in the environment), become the content of its KBO. Throughout its lifetime, an ARb replenishes its $\mathrm{KBO}$ with new images it has seen and sounds it has heard with appropriate explanations and verbal algorithms.

The teacher's task is to help the ARB to "master" the first 100-200 words, and the grammar of the NL, on the basis of images, photos and films, and to establish a dialog: teacher to ARb, $\mathrm{ARb}$ to $\mathrm{ARb}, \mathrm{ARb}$ to children. The teacher must check conformity of the words, concepts and ideas contained in the initial KBO to their meanings in the dictionary, and also the links between this $\mathrm{KBO}$ and the dictionary. In order to learn to read, it is necessary for a child ARb to search for new words and verbal algorithms. The teacher helps a child ARb to learn to read. He or she also monitors the correctness of algorithms and actions performed by the ARb. The teacher supervises the work of the $\mathrm{ARb}$ when it learns to write and when it attempts to create the first verbal algorithms (Smirnova, 2006; Ermakova, 2007; Vgotskiy, 2017). A necessary stage of education, like in all children, is the teacher's observation and control of the ARb's mastering of reflection: the ability to pay attention to the activity of any self, and one's own self in respect of other people and objects. Reflection is formed in a human child using special methods these may be used to form reflection in a child $\mathrm{ARb}$ as well.

Let us cite an example from the teacher's work. The teacher's task is to organize a didactic game with children, including ARbs, mastering reflection. Four children play. The teacher gives them each a pack of photographs of animals. The children open their photos in turn. The one that finds the desired thing, for example a giraffe, raises their hand and shouts "I!" After multiple repetitions, the game teaches abstract words to an ARb. For example, an ARb masters using modal verbs: "to wish (want)" and "to be able" in texts. The verb to wish corresponds with the "necessity to have" (Smirnova, 2006; Volkov, 2000). In our example, a didactic game organized in order to master reflection. It also specifies the concept of a word: the verb "to wish". Four children play. The teacher gives each of them a pack of photographs. Once when distributing packs of photographs to the players, the teacher forgets to give a pack of photographs to the ARb. Observation may cause the ARb which is deprived of its photos to refer to the teacher. The ARb sees that other players have packs of photographs and it also must have one. It "wishes" for it. The ARb's application, for example, not only a message containing a request, but also a gesture (an outstretched hand) is an important positive result. All children see the gesture and perceive it as a representation of the abstract words "I request", "I wish", "I want" (Volkov, 2000). And the teacher can install the algorithm of a gesture; "request" to them (or activate one stored in their $\mathrm{KBO})$.

At the beginning of its "life", an ARb (by analogy with a child (Smirnova, 2006; Ermakova, 2007; Volkov, 2000)) imitates humans (the teacher first and foremost) without analyzing the phenomenon it observes. For example, a human or an ARb similar to the learner ARb raises his/her/its hands, and the child ARb also raises its hand. The teacher walks and the ARb walks. Imitation facilitates the development of a child's purposeful activity (Volkov, 2000). All the instincts inherited by a child from his or her parents, for example, the instinct of fear and the principal reproductive instinct, an ARb receives from its parents in the form of "ready-made" algorithms (programs). A child, and therefore, a child ARb, inherits the imitation algorithm implicitly from its parents "ready-made", like all electronic programs (algorithms), for example, those containing commands to the robot as the model's "body" (whose devices and algorithms we do not consider). An example of the imitation algorithm: performing (copying) an ARb's actions 
by an $\mathrm{ARb}$. We shall present (informal) $\mathrm{ARb}$ functioning algorithms in a pseudocode, interpreting them in accordance with (Russel and Norwig, 2006). One can use PROLOG and LISP programming languages and their modernizations (Russel and Norwig, 2006; Luger, 2005) for implementing the $\mathrm{ARb}$ algorithms written in pseudocode.

ARb1 observes ARb2's actions over time, translates images into words, finds an appropriate algorithm inherited from its parents in its $\mathrm{KBO}$, and repeats (repetition) the "task", that is all the characteristic movements of $\mathrm{ARb} 2$ over $\mathrm{t}$. The movements perceived by the $\mathrm{ARb}$ are entered into the KBO with the help of operation Tell (Russel and Norwig, 2006) continuously. Additionally, experience-based problem solution data (data aggregate) are entered from time to time. Answers from the KBO are also recorded thanks to the Tell operation and the action is performed. Here is an example of the imitation algorithm.

function Imitation (repetition movements) return action $(\mathrm{t})$

inputs: percept

static: goal repetition movement goal: repetition of movements

state environment, home position environment - home position

$\mathrm{t}$ - counter time, $\left(\mathrm{t}_{0} \ldots \mathrm{t}_{\mathrm{i}} \ldots \mathrm{t}_{\mathrm{n}}\right)$ - time counter, counting from $0\left(t_{0} \ldots t_{i} \ldots t_{n}\right)$

goal $:=$ repetition $(\mathrm{job}, \mathrm{t})$ goal: repetition of the task

action $:=$ First repetition $\left(\mathrm{t}=\mathrm{t}_{0}\right)$

return action

action := Tell (KBO, movement) KBO query

$\mathrm{t}:=\mathrm{t}_{0}+1$ repetition

return action

action $:=$ Tell (KBO, movement)

action $:=$ repetition $\left(\mathrm{t}=\mathrm{t}_{\mathrm{i}}+1\right)$

$\ldots \ldots \ldots$

return action $(t)$

If an action is performed by the robot only (the "body" of the ARb), the algorithm contains only a command to the robot. As stated above, the programs controlling the robot elements (manipulators, pediculators, and so on.) are not considered. It is the robot device that actually works in the process of imitation. To allow an ARb to imitate a man or another android robot, the body of the ARb must be similar to a human (including clothes), and must be able to perform similar possible movements (of legs, feet, arms, hands, fingers), to sit down, stand up, and so on. Such a complex android robot is necessary only during the initial period of an ARb's life in order to implement the imitation effect. The agent ("brain") of an "adult" ARb must select for itself a ready-made, convenient and necessary "body", viewing it as an executive mechanism. By way of analogy with a human, apart from the "principal" algorithm - reproduction - the algorithms inherited by an ARb from its parents (together with its "genes"), must also ensure all the movement functions of the ARb, and all the "obligatory" functions for the "life" of the automaton. 
For example, the imitation algorithms, the request for loading batteries an ARb needs to move and power its electronic devices (voltage drop at the power devices output may initiate an ARb to give an audible signal ("a child is crying"). In the process of primary education, an ARb must master reading as well. Therefore, verbal algorithms are used: sequences of certain preset actions. We may note again: it was verbal algorithms that humans used in their creative activities for thousands of years. Reading begins with attempts to find collocations of words, and to build phrases (Smirnova, 2006; Ermakova, 2007; Vygotsky, 2017; Volkov, 2000), facilitated by illustrations of all words (except abstract ones) by photos and/or videos. In the process of learning, an ARb increases its word and phrase bank in the KBO; it must reach a skill level that allows it, after a syntactic analysis performed according to grammar rules, to associate these words with the images in the same manner: to master the text, that is to confirm the reality of the semantics of what it has read. Therefore, the necessary search for meanings of abstract words requires a number of transitions from word to word using their images. The verbal step-by-step algorithm of reading, for example, a written message, begins by carrying out the syntactic analysis of the message text. Then, the ARb carries out a search for images in the KBO for all the words or only a part of the text. Words may have the same or similar attributes. Then the ARb replaces, if it is necessary and possible, attributes in the images of the words found in its memory by the words present in the text. After that, if it finds it necessary and if it is possible, it sequentially builds a full image of the first phrase of the text (a "graphic phrase"). Then the last step follows: a transition from images to words from the text phrase and (if, according to the child ARb, the semantics correspond to the reality of the stated text) a transition to the next phrase. After the verbal algorithm "reading" is checked by the teacher, it is remembered by the ARb and is used by it throughout its lifetime.

Next, consider another verbal algorithm (like all the other algorithms executed by an ARb): the ability to write. It may be considered to be feedback of the "reading" algorithm. It is a text recording operation, performed according to a "video scenario" drawn up by the ARb: a film consisting of words known to the ARb and having images, with the addition of abstract words in accordance with the semantics of the text proposed to the ARb. Formation and presentation of phrases from images and words conveying the semantics of the ARb's message is the beginning of its own thinking (Vygotsky, 2017).

In this way, the ARb becomes fully capable of communicating. The ARb can transmit and receive oral and written messages. At this stage of primary education, we can consider that a new "artificial human child" has emerged. This child has an artificial body (including head elements). Also, all its actions, its sensors (for example, "eyes", "ears"), its "instincts", and its movements are powered by electric energy. But it is capable of speaking, writing and reading at an elementary level, and can even create simple verbal algorithms, that is it is capable of "primary thinking".

During its primary education, an ARb executes only simple algorithms (Volkov, 2000). Its own actions are partially based on the imitation algorithm, ready-made algorithms, and direct instructions of the teacher, etc. For example, in an imitation of a human, in accordance with an algorithm, for example, received from its parents, an ARb wiped its feet when entering a room. Next time, the child may execute this procedure taking its own sequence of actions (that is, a verbal algorithm) from the KBO as a model for executing these actions. In another case, when an $\mathrm{ARb}$ entered a house, it changed its shoes and left its outdoor shoes in an allocated place. As a result, it can use specific algorithms. This means that an algorithm has been entered into the KBO: "If I enter a building from the street, then I must wipe my feet or change my shoes". That is how a child ARb learns "common" logic at the same time. The achieved skill: reading (i.e. seeing images of objects and phenomena corresponding to the semantic meaning of a message) 
and writing (that is, describing what has been seen in words) allows learner ARbs to - not only directly but also remotely-communicate among themselves and with humans.

An example of the first (the initial actions of an ARb): The group goes out for a walk. It includes the teacher, children and all ARbs. ARb-1 saw a bird flying in the sky. Its KB includes examples similar to what it has seen: a bird, a bee, an airplane flying in the blue sky. All the films (film frames) are provided with notes and audio recordings. ARb-1 masters "flies" and plays the audio "flies!", whereupon it raises its hand or finger, pointing (in imitation of the teacher) to the sky. ARb-2 stands nearby. He finds a confirmation in a similar fashion and points to "flies". Other ARbs and children also point to the sky. Some of them find and play a full audio recording under the image: "bird flies", and one or two ARbs and children "meaningfully" (for an ARb that means consulting images in the KB) follow suit: "bird flies". ARbs store this episode in their KBOs. Another example: later on, when an ARb has already mastered reading and writing, the $\mathrm{ARb}$ receives an oral invitation: "Come!" It means "to play in the gym". The ARb draws up (stores in its running memory) a verbal algorithm: Walk to the door / open the door / walk down the corridor / open the gym door / come in /, and the ARb can follow the "invitation".

We should note that the speech recognition system seems to be the most complicated one of the sensor systems that connect an ARb with the environment, and that it has not been mastered fully yet (Galunov and Galunov, 2001). In many cases, the task of recognizing a natural "mother" language, and moreover other languages, seems very complicated even for humans. Communication between ARbs, as well as understanding humans imitating ARb speech, does not pose any problems. The reason is that the speech phonetic of ARbs is "standard". This means that the words recorded by some ARb were pronounced distinctly and loudly enough by a teacher of a specialist speaker. However, it may be necessary for the interlocutor to switch to reading a written text, so that an ARb might understand his/her speech. If speech recognition systems do not reach an acceptable performance level for an automaton, the ARb must receive electronic reading and writing algorithms from its parents. The respective algorithms are presented in our work (Salski, 2018).

The verbal algorithms presented by us are only examples. Even for "pre-school" education, an $\mathrm{ARb}$ will need many other algorithms, moreover for continued education and "service". It is important that all algorithms created by an $\mathrm{ARb}$ and nearly all algorithms received and perceived by an ARb (except "instincts") are verbal, like human ones.

The achieved skills like, for example, (1) speaking and reading, (2) seeing images of objects and phenomena corresponding to their semantic meaning (as well as understanding speech and writing), (3) describing the things previously seen and heard in words, allows a learner ARb to communicate with its fellow robots and with humans.

Knowing a language and a "common" logic, communication practice in a "daycare center" will allow the ARb to gradually learn the discursive method of "thinking" (Vygotsky, 2017; Volkov, 2000):

In conclusion, we shall cite an important example. A boy aged approximately 2.5 years is sitting on a floor and pushing a small toy car on the floor. The street is marked out by toy blocks. In some places, two blocks are placed in the form of one on the top of the other. The car moves slowly there. "Why?" "These are pedestrian crossings!" Then the car halts to a dead stop near a broken toy locomotive (that has no wheels). "Why?" "Traffic police!"

A virtual world is built by the child on the basis of his imagination. Imagination is a cognitive process and its development may be only based on abstract thinking which needs a tool; a natural language. A child is already a human, and not an-even most developed (for example, Chimpanzee) — animal (Yashina, 2013; Zorina and Poletaeva, 2005). A human also cannot inherit 
a "ready-made" imagination and fantasy in genes from his or her parents. A human acquires these abilities when he or she masters a natural language and communicates in this language.

The author has observed such scenes many times. A playing child has imagination and fantasy. Without effort, the child transfers the real world into the virtual world with the help of reason and a great tool; a NATURAL LANGUAGE. It is a HUMAN that is crawling on the floor!

The new approach and method of creating an automaton which knows a natural language and is capable of communicating with humans and its fellow automatons, allows us to say that a child ARb can play with a toy car in the same way as a human child can.

\section{Reproduction of ARbs}

For the reproduction of ARbs accompanied by a growth of intellect in the "descendants", automatons are assigned the basic life instinct- "a life purpose", the main evolutionary factor which ensures the sequential cognitive development of the "population" of Arbs-propagation. For that purpose, we divide all ARbs into two genders: ARb-HE and ARb-SHE. The gender division of exactly identical ARbs allows us to realize the main target function of the ARbs; an urge to unite with an $\mathrm{ARb}$ of the opposite gender as well as to jointly produce maximum numbers of high-quality (that is. capable of training and learning) "progeny".

The "life purpose" and "propagation" of ARbs are based on the following concept. We assume that everything irrational in human behavior is the impact of instincts: our ties with the animal world. Propagation is the principal instinct of all fleshes. Actually the main "propulsive force" and the global purpose of life is propagation. For present-day civilized humans, the basic instinct is nearly "purely" sexual now. However, this change in "human nature" cannot be considered as progressive. Therefore, it is logical to adopt propagation as the principal life purpose for ARbs. As we know, evolution created a multitude of less intellectual prototypes before the consequent, incremental creation of human intellect. We propose the reproduction of the process of consequent cognitive and general evolutionary development of humans in a population using our own method. For the reproduction of ARbs accompanied by the growth of intellect in the "descendants", artifacts are assigned the basic life instinct; that is "a life purpose". the main evolutionary factor ensuring sequential cognitive development of the "population" of $\mathrm{ARbs}$ is propagation. This is achieved by implementing the principal target function of each ARb: striving to unite with an $\mathrm{ARb}$ of the opposite sex, and to produce jointly a maximum number of quality "progeny". An ARb that was successful in the implementation of its principal function must have an advantage in the process of competitive "natural selection" of a partner to unite and create progeny with. Imitation of properties inherent in sexual propagation, heredity and natural selection, must facilitate acceleration of the evolution of a population of reasonable automatons thanks to improvement of the ethno-genotype of individuals. Therefore, the improvement of cognitive capabilities of individual agents is the main channel of transfer of their ethnic characteristics. An agent can, and must, set other goals besides the main one, which on its own depends on the success in perception, training, receiving knowledge, communication, planning, and effecting actions achieved at present by existing agents (Russel and Norwig, 2006; Gorz, Schneeberger, and Schmid, 2014; Luger, 2005). An ARb population is a multiagent system. It consists of several generations of ARbs, and it is similar to well-known and implemented multiagent systems (Ferber, 2001; Gorodetsky, 1997) in which the number of agents in a system is increased considerably. Every agent in an ARb population strives to improve its education, to 
enhance its knowledge, and to "advance" in the community of ARbs and humans in order to be popular with ARbs of the opposite sex in accordance with its principal target function.

The ARb software (SW) must primarily consist of a complete set of programs - a program pack (PP) of an up-to-date learning agent (Russel and Norwig, 2006; Gorz, Schneeberger, and Schmid, 2014). Additionally, the ARb-SW set includes a PP that performs the propagation functions in an $\mathrm{ARb}$.

Propagation of ARbs imitating the sexual propagation of higher animals and humans consists of the joint creation of a new ARb ("progeny") by "parent" ARbs. After an AR-HE and an ARSHE have found each other and joined in order to procreate, they transmit programs into hardware prepared beforehand. After the transfer of a full set of necessary programs, the process of uniting "parent" ARbs is finished, and the "life" of their "progeny" starts. Afterwards, the progeny is taught by, and teaches, itself. It must receive both ontological and epistemological knowledge from four sources: (1) "by inheritance" from "ancestors", (2) from training and scientific literature during education and self-education, (3) from communication with other ARbs and humans, and also (4) from its employer.

For creating a progeny, parents transfer a certain number of programs to it. Each program of the parental PP is divided into individual blocks. Such splitting of programs into blocks is used in certain programming methods (Bukhardt,1997; Pekhov, 1994). A program block performs certain functions and contains a certain part of information. A block must have such input and output operators that make it replaceable. It may be replaced by another block performing the same functions but having other components and other attributes. Let us call such an elementary program block "a gene" (Zhimulev, 2003; Schader and Rundshagen, 1996). In a particular case, a "gene" may contain a whole program. We shall call each program a "chromosome", which consists of genes that have a certain sequence order in the general structure of the program. A certain numerical code is assigned to each gene and to each chromosome. Gene and chromosome codes also include the dates of their creation or substantial updates, the sequential number of the respective $\mathrm{ARb}$ generation, and the $\mathrm{AS}$ type. An individual $\mathrm{ARb}$ code consists of all these information, including gene and chromosome codes. An ARb needs such information when choosing a partner for creating progeny. Each gene has a number of attributes (functional purpose, reliability, effectiveness, brevity, etc.). These attributes of an "adult" ARb are appraised by experts on a multipoint basis. That is to say, an expert board must formalize the quality attributes of a program and its part (a block), and denote them by prime numbers. Positive traits, which are stronger than the average for all similar genes (including those with other ARbs), qualify the gene appraised by the respective trait for the "dominant" class (D). Negative traits, being relatively weak, relegate the respective gene to the "recessive" class (R). We conventionally adopt in our model that a "dominant" gene has a higher "quality" than a "recessive" one. Such a quality (appraised) dispensation does not correspond to the scientific definitions of the "dominant" and the "recessive" in biology, but we adopt biological inheritance mechanisms on the basis of imitating an approximated version of Mendel's laws. In particular, in the proposed $\mathrm{ARb}$ model, it is presumed that inheritance must occur according to a law under which genetic traits $\mathrm{D}$ and $\mathrm{R}$ are formed in the succeeding generations with a probability relationship of 3:1, as regards each trait being the main one for the respective block (the second Mendelian law). A dominant gene is transferred to the progeny with a probability of $75 \%$, while a recessive one for the same trait, with a probability of $25 \%$. Recessive genes are lost with a probability of $25 \%$, but in $25 \%$ of cases they manifest themselves. The remaining $50 \%$ (all genes are stored in the ARb memory) are transferred to the progeny with the same probability. 
The sets of ARb-HE and ARb-SHE chromosomes are identical. However, each ARb has a single "sex" chromosome. The ARb-SHE sex chromosome has XX code, the ARb-HE chromosome has an XY code. This is the only difference between ARbs of different sexes. Sex chromosomes $\mathrm{XX}(\mathrm{ARb}-\mathrm{SHE})$ and $\mathrm{XY}(\mathrm{ARb}-\mathrm{HE})$ are transferred to the progeny with $50 \%$ probability.

The known methods (for example, genetic algorithms and the stochastic beam search option (Russel and Norwig, 2006)) are not suitable for our model. Therefore, we shall use the fuzzy logic apparatus for imitating the Mendelian laws: search for the optimum gene (from two possible ones).

All $\mathrm{ARb}$ programs whose improvements render a positive influence on the cognitive development of the progeny are presented in the form of genes and chromosomes. According to "Mendelian laws", they are transferred to the progeny.

"Generative mutation" may occur during the primary formation of a progeny. If their effect is negative, it must be eliminated (corrected). Determined ("crisp") calculation methods are used to control the quality of new chromosomes received by the progeny with the help of fuzzy logic methods. The principle of creating progeny by merging the software of two existing agents is, to some extent, expansion and automation of the "inheritance method" in object-oriented modeling (Pekhov, 1994; Zhimulev, 2003). During its lifetime, an ARb may update all its programs except the main target function programs that are protected from the interference of the ARb, e.g., by "embedding" them into hardware. We should note that, in the case of a robot in the model being powered by a battery, the ARb algorithm requiring its charge ("feeding") may also be "embedded".

Using fuzzy logic is a step towards the imitation of human meditations in a natural language, that have nothing in common with the calculation procedures of a computer by a computer's AI. When a human meditates, he or she operates using concepts from a natural language. However, concepts as rules, cannot be expressed. Therefore, it is very important to make computer AI use natural languages instead of algorithmic ones. Using fuzzy logic with its linguistic variables is the first step of such a changeover (Zimmerman, 2001).

Each chromosome of an $\mathrm{ARb}$ consists of a set of genes. When the fusion of a male $\mathrm{H}_{M}$ chromosome and a female $\mathrm{H}_{\mathrm{W}}$ chromosome takes place, the best gene is chosen from two corresponding ones, located in their chromosomes at the strictly determined positions of the parents' genes. As a result of this fusion, we get a new chromosome: a progeny chromosome $\mathrm{H}$, each gene of which must be improved by the choice performed. We should note that theoretically we can presume a particular case when all genes of a $\mathrm{H}_{\mathrm{M}}$ or of a $\mathrm{H}_{\mathrm{W}}$ chromosome would be of higher quality than those of the other parent's chromosome, and the progeny chromosome $\mathrm{Hp}$ would be identical to one of the parent's chromosomes.

In order to appraise the qualities of a chromosome and a gene, we shall introduce into our consideration a critical characteristic (CC) of chromosomes $\mathrm{H}$, and a critical characteristic of genes " $g$ " of the elements of these sets. The CCs of genes are obtained on the basis of the genes' precise fulfillment of their functional purpose, and the requirements for their operational speed, reliability, and so on.

Let us assume that the CCs of genes have already been determined using the fuzzy logic methods and write down the operation of the fusion of the $\mathrm{H}_{M}$ and $\mathrm{H}_{\mathrm{W}}$ chromosomes, i.e. fuzzy sets. In view of the facts that the CC values of genes " $\mathrm{g}$ " are elements of fuzzy sets $\mathrm{H}_{\mathrm{M}}, \mathrm{H}_{\mathrm{W}}$ and $\mathrm{H}_{\mathrm{p}}$ (Zimmerman, 2001). Let the fusion operation of fuzzy sets (chromosomes) be in the following form: 


$$
\mathrm{H}_{\mathrm{p}}=\mathrm{H}_{\mathrm{M}} \cup \mathrm{H}_{\mathrm{W}}=\left\{\mathrm{gi} ; \mu_{\mathrm{M}} \cup \mathrm{w}(\mathrm{g}) \mid \mu_{\mathrm{M}} \cup \mathrm{w}(\mathrm{g})>0\right\}, \forall \mathrm{g} \in \mathrm{G}, \mu: \mathrm{G} \rightarrow[0,1] .
$$

$\mu_{\mathrm{M}} \cup \mathrm{w}(\mathrm{g})$ is the maximum operator and is equal to $\max \left\{\mu_{\mathrm{M}}(\mathrm{g}), \mu_{\mathrm{W}}(\mathrm{g})\right\}$. Also, $\mathrm{G}$ is the fundamental set. (2)

Thus, according to (1) and (2), a progeny chromosome $\mathrm{H}_{\mathrm{p}}$ will receive from the parents (i.e. from two respective parents' genes) maximally dominant genes.

For membership functions $\mu($.$) in (1), (2), etc., indexation has been simplified: \mathrm{H}_{\mathrm{M}}$ 's and $\mathrm{H}_{\mathrm{W}}$ 's indexes are represented by $\mathrm{M}$ and $\mathrm{W}$, respectively.

Fuzzy sets (chromosomes) have singleton shapes because of the discreteness of the elements of these sets (CC genes). The CC of a gene whose quality (that is dominance) is rated on a multipoint basis as an element of a normed set of CCs must be within the limits of $[0,1]$. E.g., if the ten-point gene CC appraisal system is used, it is within the range of $[0,1]$. So, we will have D $=0.1,0.2, \ldots, 1.0$.

Let us note a fuzzy set of critical characteristics (CCs) of progeny chromosome genes through the CCs of genes, which are elements from a set, and their membership degrees:

$$
\mathrm{H}_{\mathrm{p}}=\left\{\left(\mathrm{g}_{\mathrm{pi}} ; \mu_{\mathrm{H}}\left(\mathrm{g}_{\mathrm{pi}}\right)\right), \mathrm{i} \in \mathrm{I}\right\}, \forall \mathrm{g} \in \mathrm{G}, \mathrm{I}_{\mathrm{II}}=\mathrm{k}
$$

In (3), a pair of values $\left(\mathrm{g}_{\mathrm{p}} ; \mu_{\mathrm{H}}\left(\mathrm{g}_{\mathrm{pi}}\right)\right)$ is the $\mathrm{i}^{\text {th }}$ element of a singleton set and its membership degree, i.e. the dominance of a gene as an element of the $H_{p}$ set, $k$ is the number of elements in a set.

Let us designate chromosome numbers with indexes $i, j \in J,|J|=S$, where $S$ is the number of the progeny's or another ARb's chromosomes. All ARbs must have the same number of chromosomes.

According to expression (3), the module of the fuzzy singleton set (e.g., $\mathrm{H}_{j}=\mathrm{H}_{\mathrm{p}}$ ) is

$$
\underset{i \in I}{\left|H_{j}\right|=\sum_{i j} \mu_{i j}\left(g_{i j}\right) .}
$$

And, regarding (3) and (4), we obtain the relative (mean arithmetic) value of the chromosome dominance modulus as follows:

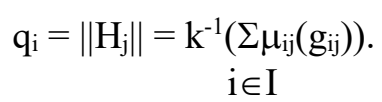

In expression (5), the mean arithmetic dominance of chromosome "q", can be considered as a chromosome quality indicator. After controlling by the determined ("crisp") method, this indicator must be compared with the standard agent chromosome dominance values.

It is evident that according to (1), (2) the average dominance of a progeny chromosome according to (5) will be, as a rule, higher, and cannot be lower than the average dominance of the chromosome of the parent who had a higher dominance.

The CC of each gene g must be considered as a fuzzy set, whose elements are the individual quality traits of a gene: functional reliability, brevity (minimum number of lines), structural stability, and so on. 
The expert appraisal method must be used as well, in order to obtain values (points) for each component of the gene $\mathrm{CC}$. When calculating the dominance of a gene, we must take account of the rating of this gene, that is its functional purpose, the complexity of its algorithm and its technical execution, its role in the chromosome in question, etc. An agent's chromosome is rated using the same method. The maximum dominance value of a series of genes may be limited because of their rating. The dominance of a $\mathrm{CC}$ may also be determined on the basis of weight coefficients. The CC value of a gene may be calculated as an arithmetic mean, if the CCs of its components are known.

Let us call the first operation according to (1), as it is adopted (for example, in the so-called "simple" method of genetic algorithms (GA)) a propagation operation (RO). Therefore, a RO operator is a fuzzy-logic operator; a union. After a RO is carried out, a set remains in the progeny's memory, wherein the CC values of genes coincide (formally) with the $\mathrm{CC}$ values of the genes in the set created after the fuzzy-logic operation of intersection of the parents' chromosomes.

The "residual" set for the progeny's chromosomes after a RO according to (1) has the following form:

$$
\mathrm{H}_{\mathrm{po}}=\mathrm{H}_{\mathrm{M}} \cap \mathrm{H}_{\mathrm{W}}=\left\{\mathrm{g} ; \mu_{\mathrm{M}} \cap \mathrm{w}(\mathrm{g}) \mid \mu_{\mathrm{M}} \cap \mathrm{w}(\mathrm{g})>0\right\} .
$$

$\forall \mathrm{g} \in \mathrm{G}$, where $\mu_{\mathrm{M}} \cap \mathrm{w}(\mathrm{g})=\min \left\{\mu_{\mathrm{M}}(\mathrm{g}) ; \mu_{\mathrm{w}}(\mathrm{g})\right\}$ and indexing is simplified, as in (1).

Let us consider the genes from the "residual" sets as recessive. Together with the parents' chromosomes, they are entered into the progeny's Inheritance Bank as a part of its Knowledge Base. Let us present the multitude for the progeny's chromosome (1) in the form where the set of elements will be put in order by the modules of membership degrees with dominance values, decreasing from left to right:

$$
\mathrm{H}_{\mathrm{pu}}=\left\{\mathrm{g}_{\mathrm{pu} 1}, \mathrm{~g}_{\mathrm{pu} 2}, \ldots, \mathrm{g}_{\mathrm{puk}}\right\}, \forall \mathrm{g} \in \mathrm{G},
$$

where index $u$ meaning an ordered form of noting sets is added to the designation of the progeny's chromosome. Functionally identical elements of fuzzy sets (genes) may belong to different fuzzy sets (chromosomes) and have different membership degrees in them. Therefore, genes having a low dominance in one chromosome may have another, for example, a higher dominance in another, chromosome. After putting chromosome records in order and comparing all CCs, approximately $25 \%$ of the most "recessive" genes (on the right according to (6)) are deleted. The rest of the genes descend in a random manner to the progeny of the following generations (into their Inheritance Banks).

As in biology, we shall call a spontaneous modification of genes in an ARb a mutation operation (MO). A MO consists of two stages. The first one is the detection of genes or a linkage of genes with identical codes. They may be located in the same chromosome, but the probability of their being found in other chromosomes, as well as in the Inheritance Bank, is much higher. The second stage of a mutation operation consists of replacement genes located in chromosomes by new ones, detected with the same code, and with a higher dominance than those being replaced, that is chromosomes with a higher dominance are chosen. The number of genes in chromosomes with a high dominance will increase from generation to generation; therefore both the cognitive abilities of an $\mathrm{ARb}$, and the adaptation of an $\mathrm{ARb}$ and the whole $\mathrm{ARb}$ population to the environment and to the work they perform will improve. 
Each agent is appraised by its qualitative characteristic. For the rth agent of an ARb, such a characteristic $\mathrm{CC}[\mathrm{r}]$ is determined as the product of the dominance modulus " $\mathrm{q}$ " (according to (5)) by the number of chromosomes $\mathrm{S}$ of the respective $\mathrm{ARb}[\mathrm{r}]$, that is

$$
\mathrm{CC}[\mathrm{r}]=\mathrm{q} \mathrm{S}[\mathrm{r}] .
$$

For full "quality appraisal" of an adult $\mathrm{ARb}$, the following calculation must be taken into account: its own $\mathrm{CC}[\mathrm{r}]$ and the $\mathrm{CC}[\mathrm{r}]$ of its progeny. A high $\mathrm{CC}[\mathrm{r}]$ value will secure an advantage to an $\mathrm{ARb}$ when searching for a partner for fusion and creating progeny, that is, in "natural selection" in an ARb population.

Let us note (using (5)) the expression of the average difference between the dominance values of all $\mathrm{S}$ chromosomes of the progeny, as compared to the arithmetic mean of the parents' chromosomes. For an "n" generation progeny:

$$
\mathrm{Q}_{\mathrm{pn}}=\underset{\mathrm{j} \in \mathrm{J}}{\mathrm{S}^{-1} \sum\left[\mathrm{q}_{\mathrm{pj}}-0.5\left(\mathrm{q}_{\mathrm{Mj}}+\mathrm{q}_{\mathrm{Wj}}\right)\right],}
$$

where $\mathrm{q}_{\mathrm{pj}}, \mathrm{q}_{\mathrm{Mj}}$, and $\mathrm{q}_{\mathrm{wj}}$ are mean arithmetic dominancies of the progeny's chromosomes and those of its parents. Let us designate as an evolutionary factor "e" of an ARb population, the difference

$$
\mathrm{e}=\mathrm{Q}_{\mathrm{p}(\mathrm{n}+\mathrm{m})}-\mathrm{Q}_{\mathrm{pn}}
$$

where $\mathrm{m}=1,2,3, \ldots$

Factor "e" is the ARb population "health" indicator. In order to obtain a reliable appraisal of the evolution of an ARb, it is necessary to compare "e", according to (7), at $m=1,2,3$ or 4 . When evolution in an ARb population is normal, e $>0$ is the necessary condition. This can be found as a result of calculating "e" after 2 or 3 or more generations. Stagnation and degradation may be the result of parents" "inbreeding", for example. Inbreeding, in its turn, depends on population size to a significant extent, just as in wildlife. The role of MOs in ARb models is important, because positive mutations influence the progressive development of the population.

During the approximation of biological propagation processes, we have excluded the crossing over operation. Because in such a heredity model, crossing over may negatively impact on generative mutations that are important for our model (Pekhov, 1994).

For verification or correction of the maximum dominance value of a progeny's gene chosen from two respective parents' genes using fuzzy mathematical methods, we use determined ("crisp") methods (Stalsky, 2014). The correctness of the choice of a gene with the maximum CC value for progeny out of parents' two genes is controlled using a discrete programming method. As a result of using this method, we get that every ith progeny gene $\mathrm{g}_{\mathrm{p} i}$ is determined by the formula:

$$
g_{p i}=\left\{\begin{array}{l}
g_{M i}, \text { if } g_{M i}+\varepsilon \geq g_{w i} \\
g_{w i}, \text { if } g_{M i}+\varepsilon<g_{w i}
\end{array}\right.
$$


where $g_{M i}$ and $g_{W i}$ are parents' ith genes.

Expression (8) is the solution of the problem of maximization of $\mathrm{CC}$ of the $\mathrm{H}_{\mathrm{p}}$ chromosome. Thus, the control of creation of the progeny chromosome $\mathrm{H}_{\mathrm{p}}$ is carried out using fuzzy logic methods, that is, checking the solution of the task of choosing the highest $\mathrm{CC}$ value for each gene of the progeny chromosome from two respective parents' genes by "crisp" mathematics.

Introducing a preset sensitivity threshold " $\varepsilon$ " in the formula (8) allows us to set the value of acceptable deviations when calculating the maximum $\mathrm{CC}$ values using fuzzy mathematical methods.

A more detailed description of the proposed $A R b$ propagation method is presented in our article (Stalsky, 2014), which includes a full development of formula (8), an example of a search for a chromosome with a higher $\mathrm{CC}$ value, and so on.

Using the proposed $\mathrm{ARb}$ propagation method is due to the concept of the maximum similarity of an artificial human (which we create) to the natural one (which is adopted in our work). However, during an experimental check of the proposed ARb propagation method, it may be found that creating genes from parts of programs is difficult in many cases and that positive generative mutations occur too rarely. In this case, the low efficiency of using Mendelian laws for artifacts will make it necessary to reject imitation of these wildlife laws. In this case, expert appraisal directly determines the CCs of all the principal programs and the progeny ARb will get from its parents the best (of two possible ones) programs for all algorithms. Several ARb generations later, parent ARbs will join the expert board, and choosing the best $\mathrm{CC}$ will become better reasoned.

\section{Further Education and Prospective Development of ARbs}

Further education of an $\mathrm{ARb}$ and its communication in a collective must broaden its perspectives, erudition, and the circle of the ARb's "friends" among its fellow learners and humans. Equipping ARbs with speech perception and propagation devices is an important step in enhancing and improving communication between ARbs and humans, and therefore improves the cognitive development of ARbs. An ARb-to-ARb dialog does not cause any problem to the agents. Actually it can flow at the same rate or even faster than a dialog between humans. A dialog between an $\mathrm{ARb}$ and a human depends on the speed and quality of speech recognition systems (Pirani, 1990) and, in the case of a failure in speech perception, it has to take place in a written form. In this case, the effectiveness of ARbs' communication with humans will naturally decrease; nevertheless, an ARb will possess abstract "thinking" in a natural language, accompanied by the development of imagination and fantasy. Perception and utilization of speech in a written form by ARbs is described in our work (Stalsky, 2014).

Equipping an $\mathrm{ARb}$ with speech perception and reproduction devices from birth will accelerate the initial cognitive development of the agent. Later on, during the education of the agent, simultaneous learning of a natural language in written and oral forms will enhance the effect of imitating humans in a collective and, subsequently, in learning various information of both a general and a scientific nature. It is important that oral speech and dialogs will render a significant positive influence on an ARb's cognitive abilities; both in its "childhood" and "adulthood" (Chomsky,1968; Sosnovsky, 2005).

For the overall development, an AP must be allowed to have time that will afford the AP the opportunity for general cultural development, and forming friendly (personal) relations - 
socialization. As soon as each adult ARb has a marked individuality, it fully recognizes itself as a member of society in its own right. Primarily, as a member of an ARb community where it must look for a partner for propagation, but also as a member of a community of humans, in particular, its "fellow workers". In the process of further education, and also after beginning regular work activity, the ARb's individuality is fully demonstrated. Back at the start of its "life", images received by an $\mathrm{ARb}$ from the observed environment (including the virtual one) are dependent, in each specific case, on the viewing angle, the lighting, and so on. The methods of phrase construction and semantic accentuation in them may also differ significantly from ARb to ARb. On different occasions, images of objects and actions may differ from one another even in the memory of one and the same ARb. In different ARbs such differences will be even greater. The development of an $\mathrm{ARb}$ from simple memorization of objects and phenomena to mastering algorithms. At first, independent synthesis of simple verbal algorithms are used in practice, and later, new and more complicated algorithms, which follow its own route that is original to some extent in every ARb. Individual perception of certain common "vital" information about humans and other ARbs is important for every ARb as well (Russel and Norwig, 2006; Gorz, Schneeberger, Schmid, 2014; Vygotski, 1982; Volkov, 2000). An ARb can master two or three languages simultaneously with greater ease than a human. The names of one and the same object in different languages will allow an $\mathrm{ARb}$ to determine the names of observed objects and phenomena, or to describe a scene more reliably and more precisely. For example, learning two languages and the availability of detailed NL-1 - NL-2 and NL-2 - NL-1 dictionaries will facilitate an $\mathrm{ARb}$ in the search for matches between words and actual concepts. The most difficult search is for semantic matches for abstract words, and it will ensure the learning of the meanings of homonyms. Knowing several languages positively influences the erudition and the area of thought of the ARb. Learning languages may be necessary for the ARb in its "job" (for example, in its "machine translation") and, if the ARb is highly intellectually developed, in its research work. It is known that the memory of a human brain accumulates information throughout his or her life not only directly in the form of texts (that is oral and written statements perceived by him or her) and not only because of images (scenes) which are seen and perceived by him or her in the environment, or even in the form of static and dynamic images on various media, but also indirectly. That is to say, a human or an ARb can also memorize notions received from texts they have heard, read, or even fully imagined (Vygotski, 1982; Sosnovsky, 2005). In the future (that is several ARb generations later) these notions of ARbs may become new and original works of art and science.

The above characteristics and progresses of an ARb in some areas of knowledge are the basis for the specialization of an ARb, in which it receives a specific kind of specialized education, a certain "interesting" work assigned to an ARb, or the ARb's circle of business and personal contacts.

For the socialization of an ARb during its "adulthood", the automaton must always be in a collective of its fellow automatons and humans. In order to avoid inbreeding, it is necessary to have a certain number of ARbs as early as at the start of their functioning, for example, 20 or 30 automatons, which must differ in respect of their basic hereditary programs. The only difference in those programs that carry out exactly the same functions is in the aspect which makes it possible to choose the best ones for transferring them to the progeny. Parents also transmit their knowledge to the progeny, in the form that is possibly transformed by those which they think will help the progeny in its education and life. This knowledge, including verbal algorithms, is stored in the memory of an ARb from the moment of its "birth" and may be used by it as it matures. 
An adult $\mathrm{ARb}$ must gradually move away from looking like an autistic human. On the basis of an active propagation algorithm, it must strive to distinguish itself by its achievements and to find itself a "mate" for creating progeny. It must form a certain "artificial libido". It is important to point out the necessity of developing libido in an $\mathrm{ARb}$, since without a libido a human is an "artificial human" and cannot be a fully-fledged personality, never mind a creative one (Jung, 1994; Freud, 2010).

The process of the normal mental development of a human being is predetermined by libido. (Sosnovsky, 2005; Erler and Rother, 2011). It is an important characteristic of an individual that is tightly linked to what may be called "natural selection" in human population. It is assumed that even animals have some form of libido (Poole and Mackworth, 2010). Therefore, a reproducing ARb must acquire an "artificial libido" that will determine its "psychic energy" (Jung, 1994; Erler and Rother, 2011). In a human, all signals "from without" impacting physiological processes are received by his or her brain and to some extent, processed by thinking. We can hope that the same process will take place in an electronic man, but in a more "determined form". An ARb will acquire emotions that become developed in the organic world from innate instincts. Therefore, "artificial libido" will also be the generator of ARbs' creativity, including scientific creativity. In scientific research, a researcher ARb will even have certain advantages over a human researcher. For example, thanks to its "infinite" memory that can simultaneously contain all books, and research papers which are topical for the work performed by the research $\mathrm{ARb}$ at present, and anything else.

In mastering oral speech and the possibility of conversing, life in a society of ARbs and humans will modify propagation conditions as well. Choosing a mate will depend not only on the total critical characteristic (CC) of a future partner, but also on the personal (maybe, to some extent, emotional) preferences of each ARb. Thus, "natural selection" in a population of ARbs will be much closer to that of a "natural" human; with all the advantages and disadvantages of the latter.

We should also note that a population of ARbs differs from a generally accepted population defined by this term by the absence of an important trait ascribed to it: "a common place of habitation" (Severtsov, 2005; Futuyma, 2005). Individuals belonging to a population of ARbs may be located at any geographical point that has, for example, an internet connection. That is to say that the whole planet is the environment of the population. This will allow the expansion of the circle of acquaintances of an $\mathrm{ARb}$ and will facilitate searching for a mate for creating progeny. Thanks to continuous improvement in the quality of characteristics of the individuals who are members of a population, the evolution of the population is attained, i.e. the system improves thanks to its elements. On the other hand, it is evident that a population with a high level of cognitive development will increasingly produce high quality progeny. Thus, Darwinism allows us to hope that ARbs will improve their intelligence from generation to generation.

If an $\mathrm{ARb}$ works in a collective where the majority of members are humans, for example, in an office or institute, combining an agent with an android robot is convenient and aesthetic. If some $\mathrm{ARb}$ works with machines, combining an agent with an android robot may be impractical. For maturing an agent immediately after its "birth" and in a collective of children, an android robot (wearing the same clothes for all ARbs and children) is very important for educating a child $\mathrm{ARb}$, because it is necessary to use the imitation effect (Smirnova, 2006; Ermakova, 2007). Afterwards, however, it can be viewed as an important executive mechanism, but only one of many possible mechanisms of an agent, and the ARb can replace it with another one.

Let us, according to the literary sources available to the author, review briefly the state-ofthe-art technology in the sphere of creating "a human model". Robotics (Katzenmeier, 2004; 
Siciliano and Khatib, 2008; Hertzberg, Lingemann, and Nüchter, 2012; Bekey, 2008; Siegwart, Nourbakhsh, and Scaramuz, 2011), first and foremost, is the design of mobile robots. According to (Katzenmeier, 2004; Siciliano and Khatib, 2008; Hertzberg, Lingemann, and Nüchter, 2012), robotics has made progress primarily in the field of robot hardware. The prototypes that are already created can move (including moving on uneven terrain), sit down, and stand up (Hertzberg, Lingemann, and Nüchter, 2012). The problems concerning the ARb "body" are not considered in this article. Therefore, we shall confine ourselves to these statements. The problems connected with teaching natural languages to a computer were examined in literature on "machine translation" (Woelfel and Donough, 2009; Severtsov, 2005) that has been used successfully in practice in recent times. More often, translations from one natural language into another require only slight (but necessary) corrections (Marchuk, 1983; Woelfel and Donough, 2009). Automatic translation takes account of language grammar, declensions, conjugations, and so on, and of the changes in words connected with them. Experience of "machine translation" will facilitate the solution of problems that arise when an automaton speaks by reciting texts and when an ARb learns speech and text semantics. This must also facilitate building syntactically correct sentences. The problems connected with the sight and hearing of an agent robot were solved satisfactorily enough for the acceptable functioning of the model created by us (Russel and Norwig, 2006; Zheltov, 2010). Nevertheless, speech recognition and reproduction systems (Pirani, 1990) do not. Finally, the generalities of computer-based artificial intelligence were considered in more detail in (Russel and Norwig, 2006; Stalski, 2018; Luger, 2005; Ferber, 2001). Therefore, the research work of (Russel and Norwig, 2006) contains references to 1652 sources and also (Gorz, Schneeberger, and Schmid, 2014) refer to separate sources in respect of each theme or problem. We should particularly take into account the detailed description of the state-of-the-art of the scientific field of Artificial Intelligence in (Russel and Norwig, 2006).

We should point out the most important tasks of implementation of ARbs with a NL. Solving these problems from various subdisciplines of AI theory is necessary for the creation and development of an ARb. Sensors are essential in all video and audio systems and in speech reproduction and recognition systems. The theory and implementation of electronic image recognition systems designed for humans must be studied, and possibly supplemented, in view of being intended specially for the ARb devices (but not for humans). We can hope that a positive effect will be obtained from conditioning the output parameters of sensors with the input devices of ARbs, supplemented with temporary or permanent adaptation systems.

Another task is building a humanoid (anthropomorphic) robot. The robot must be short in height, approximately as tall as a 5-6 year old child. It must be able to move; not only to walk but also to run (at present, the Japanese ASIMO robot (Honda) can do it). There must be an elementary likeness in the face of the robot. Also, it must be able to turn its head for vision, to move its hands and fingers, and to perform body positions, for example, sitting, standing, lying. Its clothes and shoes must be similar, in appearance, to childrens' clothes and shoes. Without improving image recognition and humanoid robots as well as without the development and use of verbal algorithms, the creation of ARb is difficult.

\section{Final discussions}

The article contains a completely new solution that is applicable to the entire huge volume of artificial intelligence. It is a new approach to solving the problem that offers the creation of an AI that "independently" continuously increases its own cognitive level. At the same time, it provides 
for the growth of the cognitive level of both an individual automaton and the entire built community of automata, and due to their "reproduction", their cognitive growth from generation to generation is also provided. Of course, the proposed new approach and the possible method of its implementation require criticism (that is criticism on the merits of the proposal). It is necessary to criticize the new approach, its mistakes, and the shortcomings that make the implementation of the proposal unrealistic.

Instead, our opponents declare the new approach a "big metaphor" and point as an example to an important original solution, but a particular problem. A separate solution to a specific problem, which can be infinitely many.

In addition, our opponents also note the lack of "... guidelines for computer scientists, cognitive scientists or philosophers". However, taking a new approach, computer scientists and cognitive scientists will have to consider their considerable achievements (by taking into account the mandatory conditions of an artificial person created in accordance with the new approach). Philosophers will have to turn again to the psychological issues of people's lives, for example, checking the objective action of the "libido".

The new approach gives the automaton a language. Language is not only a verbal communication but is also an instrument of thinking and is an instrument of cognition. The automaton has speech. It was speech that gave humanity an unattainable advantage and superiority over animals. Thanks to speech, people gained intelligence and forever stood out from the living nature. Speech is a necessary tool of communication. It is the process of transition of thoughts into words and is the basis for the emergence of new thoughts and ideas.

It is also important that the new approach is based on some imitation of the Darwinian appearance of humanity on our planet. The formation of a person is closely connected with the development of speech by him/her. At first, perhaps, speech is used only for communication in the first communities and, then, speech leads to thinking, awareness of the environment, and the simplest prediction of the conditions of the coming hour, day, and future. People have elementary logic, considerations that today can be called verbal algorithms. Hence, the first steps of the mind of some $\mathrm{ARb}$ community can also be made based on logic and verbal algorithms.

The new approach is a new path that is based on and should be improved in parallel with all other sections of AI. The human mind has been developing for millions of years. To accelerate the development of the $\mathrm{ARb}$, it may be necessary to integrate it into the Arb, "with his permission", any new devices, for example, neutron networks.

\section{Conclusion}

Our article proposes a new approach to creating a model of a Homo Sapiens, with a "brain" (agent) having an AI, and a method for its implementation. An analogy between a "reasonable human" and its model which was created, is adopted as the principal concept. The adopted model must consist of an intellectual agent and a humanoid robot; that is an agent robot (ARb).

To the best of our knowledge, it is this work that proposes conditioning the development of AI by learning a natural language (NL) by an AI carrier (agent) for the first time, by speech and the development of its intellect in a collective of its fellow agents and humans. Without an agent learning a NL and without developing its intellect in a collective of ARbs and humans, one may only talk about devices and instruments possessing elements of intellect.

The article shows the fundamental possibility of creating automata with a natural language and a social environment for their development. 
The purpose (task) of our work consists of the fact that an existing intellectual agent is taken as a basis and supplemented with the organs, functions, and behavioral characteristics of a human. They include speech in a natural language that allows the usage of verbal algorithms, as well as the existence of "instincts", including the "propagation instinct", for the purpose of which electronic algorithms are used. For the implementation of the proposed new approach, we propose a method of teaching an $\mathrm{ARb}$ a natural language needed for human thinking. Reflections, abstract planning, abstract concepts and solutions in a NL allow the ARb to pass on to meaningful actions in a real world. Note that the purpose of our work can probably be achieved using other methods besides the one proposed by us.

In accordance with the proposed concept of achieving the objective, a child ARb begins its "life" in a "daycare center" collective. Several ARbs and several children picked by age learn a natural language under the supervision of a teacher. They learn how to read and write. At first, an automaton receives the algorithms it needs for "living" only in electronic form and, then, later, in the form of verbal algorithms as well. An ARb must also learn how to create and use verbal algorithms (like any human being). The intellect of an agent, like that of a human, is closely linked with its personal life, body and environment. Starting from the "daycare center" and until the end of its existence, an ARb lives in a collective with its fellow agents and humans- in a social environment.

It is shown in our article how the initial task of prime importance, creating an artificial intellect, is solved, by teaching natural language (or languages) to an agent robot and, thus, by teaching communication in a natural language with other ARbs and humans, as well as "reflections" in a natural language.

An automaton, a model of a human, is assigned a fundamental purpose in life, intrinsic to all things living: propagation. A purpose in life is a necessary stimulus for both the work and the private life of an ARb. Every agent robot "lives" in an autonomous automatic mode, and follows the objective function that imitates the sexual reproduction instinct of higher animals and humans. In their "private life" the target function ("artificial sex instinct" or even "artificial libido") predetermines the agent's striving to forestall its competitors, and to succeed in its job and in its society. In the process of "sexual propagation" of agent robots, their population gradually emerges. It develops cognitively from generation to generation, since the qualitative improvement of all-round development of "progeny" (population individuals) in the process of propagation is envisaged.

"Reasonable" agent robots, that are artifacts, propagate like living organisms in nature. The method of artifact propagation that imitates the ordinary sexual propagation of animals and humans to a certain extent. Gradually, ARbs form their own population that is by definition, an aggregate of individuals with a common origin, which forms a holistic system. The development of an $\mathrm{ARb}$ in a collective of humans and in a population of peers presumes introspection and, on this basis, an increase in extensional ontological knowledge of the agent

An adult $\mathrm{ARb}$ becomes a unique individual personality thanks to an original combination of programs transferred by parents to the progeny ("genes"), an individual perception of the environment, and processing of information received from various sources by each automaton. Having received an education and a profession, an artificial personality may replace its part, a humanoid robot it needs as a "child", with another one which is more convenient for its work and life. The agent robot proposed by us must be able to replace a human when working in an environment that is unsuitable for human existence or which presents a hazard to human life. 


\section{References}

Bauer, G. 2000. Bausteinbasierte Software. Braunschweig. Vieveg Verlag.

Bekey, G. A. 2008. Robot Learning Autonomous Robots. London: The MIT Cambridge.

Bloomfield, L. 1933. Language. NY.: Holt, Rinehart \& Winston.

Bukhardt, R. 1997. Objektorientierte Modellierung für die Praxis. Bonn: Addison-Wesley.

Chomsky, L. 1968. Language and Mind. NY.: Harcourt Brace \& World

Erler, M.; Rother, W. (Hrsg). 2011. Philosophie der Lust. Studien zum Hedonismus. Basel: Schwabe Epicurea

Ermakova, E.S. 2007. Razvitie gibkosti myshleniya u detej. [Developing Flexibility of Thinking in Children]. Saint - Petersburg: Rech Publ. (in Russian).

Ferber, J. 2001. Multiagenten-Svsteme. München: Addison-Wesley.

Forseit, D.A.; Pons, J. 2004. Komputernoe zrenie [Computer vision. Modern approach]. Moskow: Williams (in Russian).

Freud, S. 2010. Osnovnji psichologisheskie teorii v psichoanalize [Psychoanalytic studies]. Minsk: Pourri (in Russian).

Futuyma, D.J. 2005. Evolution. Sunderland: Sinauer Associates.

Galunov, V.; Galunov G. 2001. Science Perspectives of Speech Technology. SpeeCom pp. 143145.

Gavrilova, T.A.; Khoroshevsky, V.F. 2000. Baza znanii intellektualnjh sistem [knowledge Base of intelligent systems]. Saint Petersburg: Piter. (in Russian).

Gorodetsky, V.I. (Editor). 1997. Proceedings of the international seminar "Distributed control and multi-agent systems" (DAIMAS-97). St. Petersburg (in Russian).

Gorz, G.; Schneeberger, J.; Schmid, U. 2014. Handbuch der kunstliche Intelligenz. (5. Aufgabe). Münchn: Oldenburg Verlag.

Grosan, C.; Abracham, A. 2011. Intelligent Systems. A Modern Approach. Berlin: Springer.

Hertzberg, J.; Lingemann, H.; Nüchter A. 2012. Mobile Roboter. Heidelberg: Springer.

Jung, K. 1994. Libido, ego metamorfozj i simvolj [Libido, its Metamorphoses and symbols]. St. Petersburg: Progress-Uni. (In Russian).

Katzenmeier, H. 2004. Grundlagen der Robotertechnik: Tipps und Tricks für den Selbstbau. Aachen: Elektor Verlag. 
Luger J. F., 2005. Iskusstvennyi intellekt: strategii i metody resheniya slozhnyh problem/angl. [ArtificiIntellect: Strategies and Methods of Solving Complex Problems/Tr. from Engl]. Moscow: Williams Publ. (in Russian).

Marchuk, Y. 1983. Problemj mashinnogo perevoda [Problems of machine translation]. Moscow: Pedagogik. (In Russian).

Palmer J.; Palmer L. 2003. The Ultimate Origins of Human Behavior. Boston: Allen and Bacon.

Pekhov, A.P. 1994. Biologiya and obshchaya genetica [Biology and General Genetics]. Moscow: Drujby narodov [Peoples' Friendship University of Russia] Press. (In Russian).

Pirani G. 1990. Advanced algorithms and architectures for speech understanding. Vol. 1. Springer-Verlag Berlin Heidelberg

Poole, D.L.; Mackworth, A.K. 2010. Artifical Intilligence. NY: Cambridge University Press.

Rapoport, G.N.; Gerts, A.G. 2011. Biologicheskiy i iskusstvennyi razum. [Biological and Artificial Intellect]. Moscow: URSS Publ. (in Russian).

Reznikova, Z. 2002. Intellekt i jazik zivotnih i cheloveka [Intelligence and language of animals and humans]. Moscow: Aspect-Press (in Russian).

Russel, S.; Norwig, P. 2006. Künstliche Intelligenz. A Modern Approach. Second edition. Vertrag Prentice Hall.

Schader, M.; Rundshagen, M. 1996. Objektorientierte Systemanalyse. Berlin: Springer Verlag.

Schmitt, L. 2001. Theory of Genetic Algorithms. Theoretical Computer Science, Volume, Issues $1-2259$

Severtsov, A. 2005. Teorija evolüzii [Theory of evolution]. Moscow: Vlados. (in Russian).

Siciliano, B.; Khatib, O. 2008. Springer Handbook of Robotics. Berlin: Springer-Verlag.

Siegler, R.; DeLoache, J.; Eisenberg, N. 2005. Entwicklungspsychologie im Kindes - und. Jugendalter. Spektrum: Akademischer Verlag.

Siegwart R.; Nourbakhsh I.R.; Scaramuzz D. 2011. Introduction to Autonomous Mobile Robots. Massachussets: The MIT Press.

Smirnova, E.O. 2006. Detskaya psihologiya [Child Psychology]. Moscow: Vlados Publishers (in Russian).

Sosnovsky, B. 2005. Vozrastnaya psikhologiya [Developmental Psychology]. Moskow: Yuraye Publ (in Russian). 
Stalski, W. 2018. Enhancement of Cognitive Abilities of an Agent-Robot on the Basis of Image Recognition and Sound Perception (September 2018). International Journal of Artificial Intelligence and Applications (IJAIA), Vol.9, No.5.

Stalsky, V. 2014. Evolyucionnyi metod kognitivnogo razvitiya obuchayushchihsya avtonomnyh agentov. Iskusstvennyj intellekt i prinyatie reshenij [Artificial Intellect and Decision Making], No.2, pp.52-62 (in Russian).

Volkov, B.S. 2000. Doshkolnaya psikhologiya [Preschool Psychology]. Moscow: Academ. Project Publi. (in Russian).

Vygotskiy, L.S. 1982. Myshlenie i rech [Thinking and Speech]. Collected works, V.2. Moscow: Pedagogika Publi. (in Russian).

Vygotskiy, L.S. 2017. Detskaya psihologiya [Child Psychology]. Moskov: Rupol-Clasik (in Russian).

Woelfel, M.; Donough, J. 2009. Distant Speech Recognition. London: Scientific Pub.

Yashina, V. 2013. Teorija i metodika razvitija rechi detej [Theory and methodology of children's speech development]. Moskau: Akadevija (in Russian).

Zheltov, S. 2010. Obrabotka $i$ analiz izobrazenii $v$ zadachah mashinnogo zrenija [Image processing and analysis in machine vision problems]. M.: Fizmatkniga (in Russian).

Zhimulev, I.V. 2003. Obschaya i molekulyarnaya genetika [General and Molecular Genetics]. Novosibirsk: Siberian University Press (in Russian).

Zimmerman H. 2001. Fuzzy Set Theory-and Its Applications. Boston: Kluwer Academic Publishers.

Zorina, I.; Poletaeva, I. 2005. Elementarnoe mjshlenie zivotnih [Elementary thinking of animals]. Moscow: Akademkniga (in Russian). 